\title{
UBE4B: A Promising Regulatory Molecule in Neuronal Death and Survival
}

\author{
Rami Abou Zeinab, Hong Wu, Consolato Sergi and Roger Leng * \\ Department of Laboratory Medicine and Pathology, University of Alberta, Edmonton, AB T6G 2S2, \\ Canada; E-Mails: abouzein@ualberta.ca (R.A.Z.); hwu4@ualberta.ca (H.W.); sergi@ualberta.ca (C.S.) \\ * Author to whom correspondence should be addressed; E-Mail: rleng@ualberta.ca; \\ Tel.: +1-780-492-4985; Fax: +1-780-492-9974.
}

Received: 7 October 2012; in revised form: 22 November 2012 / Accepted: 27 November 2012 / Published: 10 December 2012

\begin{abstract}
Neuronal survival and death of neurons are considered a fundamental mechanism in the regulation of the nervous system during early development of the system and in adulthood. Defects in this mechanism are highly problematic and are associated with many neurodegenerative diseases. Because neuronal programmed death is apoptotic in nature, indicating that apoptosis is a key regulatory process, the p53 family members ( $\mathrm{p} 53, \mathrm{p} 73, \mathrm{p} 63$ ) act as checkpoints in neurons due to their role in apoptosis. The complexity of this system is due to the existence of different naturally occurring isoforms that have different functions from the wild types (WT), varying from apoptotic to anti-apoptotic effects. In this review, we focus on the role of UBE4B (known as Ube4b or Ufd2a in mouse), an E3/E4 ligase that triggers substrate polyubiquitination, as a master regulatory ligase associated with the p53 family WT proteins and isoforms in regulating neuronal survival. UBE4B is also associated with other pathways independent of the p53 family, such as polyglutamine aggregation and Wallerian degeneration, both of which are critical in neurodegenerative diseases. Many of the hypotheses presented here are gateways to understanding the programmed death/survival of neurons regulated by UBE4B in normal physiology, and a means of introducing potential therapeutic approaches with implications in treating several neurodegenerative diseases.
\end{abstract}

Keywords: UBE4B; p53; p73; p63; nervous system; apoptosis; neurodegenerative diseases 


\section{Introduction}

With regard to the nervous system, there is no doubt that the regulatory mechanism underlying the growth and death of neuronal cells during early development and at later adult stages is complex [1]. Many aspects of this mechanism have been revealed in normal physiology, but not in pathological situations. In neuronal development, neuronal death is considered to be part of the development mechanism during early stages, in which many neurons are programmed for death, thus avoiding any inappropriate neuronal connections [2]. It has been highlighted that this neuronal elimination mechanism is essential to removing inappropriate differentiated cells after neural precursors undergo exponential proliferation. However, this neuronal elimination is also necessary after differentiated neurons migrate to their anatomical location, in which they establish their target connections $[3,4]$. At this stage, neurons that do not receive optimal trophic support will undergo apoptosis [5]. Interestingly, neuronal death at later stages has also been characterized as apoptotic in nature in traumatic nervous system injury [6,7]. It is worth mentioning that after surviving the developmental stage, neurons become more stable and less vulnerable to injury, indicating that tight regulation of the apoptotic pathway protects mature neurons and guarantees their survival in the absence of injury [2]. This process opens a gateway for the role of regulatory molecules, which appear to be absent or non-functional at early developmental stages, yet become key factors for monitoring neural death at later stages. The apoptotic nature of neuronal death remained vague until some reports revealed that the mitochondrial death pathway is involved [8]. Such findings drew major attention to the many molecular mechanisms that are involved in the mitochondrial death pathway such as the p53 system and its role in apoptosis [9]. The p53 system is composed of three major proteins: p53, p63, and p73. p53 was the first to be identified, and its role as a tumor suppressor is critical in the field of cancer [10]. Similarly, p73 and p63, which were discovered later, also have tumor suppressor activities [11]. All tumor suppressors have been described as keepers of the genome because they monitor cell proliferation and induce apoptosis, cell cycle arrest, or DNA damage repair [10]. The role of the p53 system in inducing programmed cell death, or monitoring the apoptotic pathway and the significance of the apoptotic death of neuronal cell have suggested the possible links between the p53 system and the nervous system. In the upcoming sections, we will elucidate the role of each protein of these proteins in the nervous system, and we will present the major findings that highlight the consequence of any defects in the regulation of these proteins on the nervous system [12]. First, we will introduce a regulatory molecule that has taken the topic of a wide range of discussions in the last few years, as it is a major regulatory molecule in the 553 system.

In 2011, Wu et al. showed that UBE4B acts as an E3/E4 ligase that physically interacts with p53 and MDM2 to promote the polyubiquitination and degradation of p53 in brain tumors, thus decreasing the apoptotic activity of p53 tumor suppressor [13]. Other reports have demonstrated the role of UBE4B in regulating p63 and p73 proteins. Approximately 50\%-60\% of human tumors show mutations in $\mathrm{p} 53$; the remaining tumors exhibit a dysfunctional system despite bearing wild type (WT) [10,11]. The exact mechanism underlying the tight regulation of p53 protein is not fully understood, but it is clear that many processes are involved, including sumoylation [14,15], neddylation [16,17], acetylation and other post-translational modifications [18,19]. However, ubiquitination has been identified as the major regulatory mechanism of p53 protein [20,21]. There are 
three types of ubiquitination: mono-ubiquitination, multi-ubiquitination, and poly-ubiquitination [22]. In poly-ubiquitination, similar to UBE4B-p53, the proteosomal degradation of the substrate will be induced post ubiquitination. UBE4B is a mammalian homolog of the protein UFD2 found in S. cerversiae. UBE4B has a conserved $U$ box which confers its ligase activity [13]. As mentioned above, the type of ubiquitination controls the substrate's fate. For example mono-ubiquitination similar to that induced by the MDM2 E3 ligase does not induce proteosomal degradation post ubiquitination [23]. Previous studies have shown that UBE4B is predominantly expressed in mouse neuronal tissues [24], which has attracted increased attention to the UBE4B E3/E4 ligases. In this review, we propose that $\mathrm{UBE} 4 \mathrm{~B}$, through its regulatory action on the p53 family proteins, can act as a key factor in the development of the nervous system and can thus be a target molecule in neurodegenerative disease treatments. Also we emphasize on the role of UEB4B in the nervous system via p53-independent pathways, such as axon protection in mice and the clearance of ataxin3, which is responsible for spinocerebellar ataxia type 3 .

\section{The Role of UBE4B in the Nervous System via p53 Family Regulation}

\subsection{UBE4B and p53 in the Nervous System}

The association between $\mathrm{p} 53$ and tumor inhibition has been confirmed in $\mathrm{p} 53^{-/-}$mice, which have a high rate of tumor formation [25]. Although this tumor suppressor activity of p53 is the major focus of a wide range of cancer research, p53 may play a role in the nervous system. According to Armstrong et al., 23\% of $\mathrm{p} 53^{-/-}$female embryos were characterized with midbrain exencephaly, which results from the abnormal development of the neural tube and the overproduction of neural tissue [26,27]. Therefore, p53 was thought to have two distinct roles: one in tumor suppression and another in nervous system development. Studies analyzing the role of p53 as a transcription factor revealed the apoptotic role of these tumor suppressors by regulating genes involved in the intrinsic mitochondrial death pathway, such as Noxa, Puma, Bax, etc. [9]. p53 has also been shown to possess a transcription-independent apoptotic function by acting directly on the mitochondrion [28]. Interestingly, an investigation revealed that the exencephalic phenotype of $\mathrm{p} 53^{-/-}$female embryos was similar to the phenotype of animals that had mutations in other members of the intrinsic mitochondrial death pathway, such as caspase 3 and 9, and Apaf-1 [29,30-32]. In addition, it is important to highlight that p53 overexpression induces the death of sympathetic neurons [33]. However, these p53 knockout sympathetic neurons were able to survive when neural growth factors were removed, confirming the role of pro-apoptotic activity of p53 in the early development of the nervous system [34]. The same outcome was obtained when p53 was present but blocked after binding to E1B55K protein [35]. Many other tumor suppressor proteins play a critical role in the apoptotic pathway, and studies have shown that mutations in specific target genes of p53 result in massive levels of apoptosis in the embryonic nervous system [2]. In vivo analyses showed that sympathetic neurons during the first two postnatal weeks showed a decrease but not an abolishment of the rate of apoptosis in $\mathrm{p} 53^{-/-}$mice $[35,36]$. Moreover, the role of p53 is not limited to embryonic stages. Less is known about this aspect; however, p53 overexpression has been reported in many neurodegenerative conditions, including seizure-induced excitotoxic damage, middle cerebral artery occlusion, traumatic brain injury, and 
peripheral nerve injury as it is the case in spinal cord anterior horn cells injury [37,38]. Lastly, p53 neuronal death role was also associated with a wide range of neurodegenerative diseases that are characterized by progressive neuronal death including: Parkinson's disease, Huntington's disease, Alzheimer's disease, etc. [1].

All of these findings have drawn attention to the regulatory molecules that inhibit or trigger the expression of $\mathrm{p} 53$, particularly in neurodegenerative diseases in which $\mathrm{p} 53$ has been reported to be upregulated [39]. In the normal body system, p53 protein is continuously repressed until needed. In DNA damage, p53 repression ceases, allowing p53 to function effectively [40]. This finding indicates that defects in the nervous system may occur with any disruption in the tight regulation of p53, resulting in uncontrolled p53 apoptotic activity. UBE4B (known as Ube4b or Ufd2a in mouse) was recently identified as an E4 ligase that is essential for MDM2 to mediate the polyubiquitination and degradation of $\mathrm{p} 53$ [13]. Moreover, $\mathrm{Ube} 4 \mathrm{~b}^{-/-}$mice are embryonically lethal, diminishing the possibility that other ligases compensate for the role of Ube4b in p53 regulation [41], which is also supported by rare mutations of other E3 ligases, and excluding their role in p53 regulation at these stages [25]. E3 ligases include MDM2, which was shown to be essential for UBE4B-p53 regulation. Most important, because p53 overexpression is commonly detected in neurodegenerative diseases, defects in UBE4B regulatory mechanism are expected. Accordingly, future extensive investigations should focus on UBE4B expression and activity at the early embryonic stages to reveal how p53 proteins regulate neuronal death and development. Defects in this regulatory mechanism are not limited to the molecular level of UBE4B-p53 interaction; indeed, post ubiquitination errors might also exist. For instance, lysine residues involved in UBE4B-p53 ubiquitination are important because lysine chains have a major effect on the post ubiquitination fate of the substrate [42]. One example is E3 ligase Pirh2, which ubiquitinates different lysine residues in p53 and p73. Therefore, its degrading effect differs depending on the lysine residue used. Despite degrading p53, Pirh2 does not have the ability to degrade p73, due to utilizing Lys63 [43]. Thus, more investigations should be performed regarding the lysine residues utilized by UBE4B in p53 ubiquitination.

\subsection{UBE4B and $p 73$ in the Nervous System}

As mentioned earlier, many clues on the role of other transcription factors are associated with the role of p53 in sympathetic neuron developmental death. p73 has been suggested to play a role in the nervous system. Many studies have shown the function of $\mathrm{p} 73$ as a tumor suppressor; in particular, $\mathrm{p} 73$ transactivates a large number of p53 target genes such as $p 21$ and Bax [44]. Interestingly, it has been demonstrated that $\mathrm{p} 53$ tumor suppressor activity depends on the presence of $\mathrm{p} 73$, whereas the opposite is not required [23,45,46]; $\mathrm{p} 73$ is sufficient to induce apoptosis in the absence of p53 [47]. However, it is important to note that unlike $\mathrm{p} 53^{-/-}$mice, $\mathrm{p} 73^{-/-}$mice do not develop spontaneous tumors [45], but $\mathrm{p} 73^{-/}$mice show significant neuronal abnormalities, such as the loss of peripheral sympathetic neuron, hippocampal dysgenesis, and the majority dies before they are four weeks old [25,45]. In addition, p $73^{-/-}$SCG (superior cervical ganglion) models show a significant decrease in the number of sympathetic neuron number in late embryogenesis, suggesting an anti-apoptotic role for $\mathrm{p} 73$; these findings were confirmed in cultured and in vivo analyses [48]. The role of p73 is not limited to embryonic neuronal development, as adult $\mathrm{p} 73^{+/-}$sensory neurons were more vulnerable to death 
compared to wild-type neurons following axonal injury [49]. Furthermore, $\mathrm{p} 73^{-/-}$mice that survive after birth develop thin cortical hemispheres and enlarged ventricles [50]. In 2004, Wilson et al., reported an alteration in the subcellular distribution of $\mathrm{p} 73$, which accumulated in the nucleus and localized to neurites and neurofibrillary tangles in Alzheimer patients [51]. However, little is known about the role of p73 in neurodegenerative diseases and the existence of p73 isoforms further complicates the situation.

Unlike p53, p73 proteins exist in different naturally occurring isoforms in the human body. TAp73 isoforms appear to mimic the role of p53 in activating similar downstream genes that are involved in cell cycle arrest and apoptosis [50]. However, this is not the case for $\Delta \mathrm{Np} 73$, which lacks the $\mathrm{NH}_{2}$-terminal transactivation domain. Not only do $\Delta \mathrm{Np} 73$ proteins not play any role in apoptosis, it was proven that they possess a dominant negative "anti-apoptotic" behavior in contrast to the tumor suppressor function of p53 and full length p73 [50,52]. Reports revealed a negative feedback loop between $\mathrm{p} 73$ and $\Delta \mathrm{Np} 73$ in regulating cell death and survival [53,54]. Further analyses at the molecular level showed that the predominant form of $\mathrm{p} 73$ in developing brain and sympathetic ganglia is $\Delta \mathrm{Np} 73$ [48]. This finding led to the conclusion that $\Delta \mathrm{Np} 73$ is essential for developing both the central and peripheral nervous system because it rescues neurons from p53 apoptotic activity, and it is characterized as a pro-survival protein [55]. Additionally, the overproduction of $\Delta \mathrm{Np} 73$ in tumor cells blocked chemotherapy induced apoptosis [56]. Many hypotheses have been proposed regarding the mechanism by which $\Delta \mathrm{Np} 73$ oppose 553 and p73 apoptotic activity and the signals for such pathways. Pozinak et al. reported the binding of $\Delta \mathrm{Np} 73$ to p53 to block its apoptotic activity [48], and Irwin et al. proposed that this truncated isoform has the ability to bind the TAp73 isoform, which acts similarly to $\mathrm{p} 53$, thus abrogating its apoptotic role [50]. Nevertheless, $\Delta \mathrm{Np} 73$ regulation has remained unclear. In 2005, a study performed by Hosoda et al. revealed that UBE4B binds to p $73 \alpha$ but not p73 $\beta$; UBE4B also induced $\mathrm{p} 73 \alpha$ proteosomal degradation without promoting ubiquitination [57]. However, these results do not negate the interaction of UBE4B with other p73 isoforms, such as $\Delta \mathrm{Np} 73$. Furthermore, the SAM domain, which has been reported to be essential for UBE4B binding to p73 $\alpha$, is preserved in $\triangle \mathrm{Np} 73 \alpha$ [58]. The lack of $\mathrm{p} 73 \alpha$ ubiquitination when interacting with UBE4B raises some questions regarding the degradation process; although it has been reported that the E3/E4 ligases regulate the expression of their substrate target molecules independent of ubiquitination [57]. Accordingly, we cannot disregard the fact that UBE4B can act as an E3/E4 ligase to regulate proteins with apoptotic functions in a ubiquitin-dependent or -independent manner; this hypothesis requires further investigation. Clearly, $\triangle \mathrm{Np} 73$ was given more attention after it was shown that the neuronal apoptosis observed in $\mathrm{p} 73^{-/}$mice is only partially rescued by the absence of p53 [59], indicating that tight regulation of p73 is not dependent on p53 expression or inhibition. Other major ligases, such as Pirh2, were also reported to bind to and ubiquitinate p73, but cannot induce degradation [43]. For MDM2, the interaction with $\mathrm{p} 73$ is at the $N$-terminal transactivation domain, which is absent in the $\triangle \mathrm{Np} 73$ isoform [23]. Therefore, UBE4B might be a regulatory factor that manipulates the ratio of apoptotic p73 to the anti-apoptotic isoform, but the process at the p73 level is more complicated compared to $\mathrm{p} 53$. The role of other cofactors is highly likely, particularly because UBE4B can only degrade alpha isoform but not the beta isoform, which is triggered without any ubiquitination. Even if the fate of the substrate is degradation, the lack of ubiquitination raises some questions regarding the role of UBE4B as an E4 ligase towards p73 and its isoforms. 


\subsection{UBE4B and p63 in the Nervous System}

The role of p63 in the nervous system was first proposed by Flores et al. who showed that p63 can promote apoptosis in cell lines and act as a pro-apoptotic protein in central nervous system development when DNA damage is induced by gamma radiation [46]. The major finding describing the role of p63 in the nervous system was reported by Kaplan et al., in which the TAp63 isoform was revealed to be the predominant form in the nervous system, particularly in the developing cortex, and the high levels of this isoform were associated with the level of apoptosis in sympathetic neurons [60]. In addition, TAp63 $\gamma$ overexpression caused neuronal apoptosis even when NGF was present. Further findings supported the pro-apoptotic role of $\mathrm{p} 63 ; \mathrm{p} 63^{-/-}$cultured neurons showed significant resistance to apoptosis following NGF withdrawal [61]. In vivo analysis also revealed that embryonic p63 ${ }^{-/-}$mice developed defects in naturally occurring neuron death, and all died at birth [62]. As mentioned above, p63 and p53 targets similar apoptotic genes to induce apoptosis, and both of proteins increase Bax gene expression, which is essential for the neuronal apoptotic activity of these proteins. As discussed above, Bax triggers the mitochondrial apoptotic pathway [61]. However, in the same study, the TAp63 apoptotic activity was found to be independent of p53. This result was later confirmed by Gressner et al., who revealed that TAp63 can mediate apoptosis via other death receptor complexes such as CD95, TNF, and FLIP [63] which is in contrast to the p53 requirement of the presence of p63 to successfully perform its apoptotic activity. Cells deficient in both p63 and p73 exhibit a significant resistance to neuronal apoptosis despite the presence of functional p53. Thus, p53 is proposed to operate upstream of p63 and p73 and cannot trigger cell death by itself as proposed by Nictorea et al. [62]. Similar to $\mathrm{p} 73$, the $\Delta \mathrm{Np} 63$ isoform, which contains the NH2-terminal transactivation domain, has also been reported to act as an anti-apoptotic protein by promoting cell growth and proliferation [64]. Although little is known about the role of $\Delta \mathrm{Np} 63$ compared to $\Delta \mathrm{Np} 73$, it has been shown that $\Delta \mathrm{Np} 63$ is overexpressed in squamous cell carcinomas [65-67], and it is believed to enhance cell growth by blocking p53 mediated transactivation [64]. These findings were confirmed when the expression of p53 target genes, such as $p 21$, Noxa, and Puma, was stabilized when $\Delta \mathrm{Np} 63$ is deleted [68]. $\Delta \mathrm{Np} 63 \alpha$ was reported to be inhibited after UV and paclitaxel treatment [69], and thus, $\Delta \mathrm{Np} 63$ is speculated to act as a key factor blocking TAp63, particularly because it has been revealed to be more stable than TAp63 [70]; further investigation is required to examine this possiblity. The similarities between p63 and $\mathrm{p} 73$ in terms of their isoform functions, in which the TA isoform possess apoptotic function and the $\Delta \mathrm{N}$ isoform counteracts this function, was thought to aid a better understanding of the entire regulatory mechanism.

Unfortunately, with regard to UBE4B, the mechanism is more complex. First, the only isoform of p63 found to be regulated by UBE4B was $\triangle \mathrm{Np} 63 \alpha$, whereas TA isoform showed no link to UBE4B [68]. UBE4B binds to and stabilizes $\triangle N p 63 \alpha$, and stabilization was first noted by inhibiting ubiquitination; therefore, the degradation of $\Delta \mathrm{Np} 63 \alpha$ is a cisplatin-induced mechanism. When ectopically expressed, UBE4B efficiently extends the half-life of $\Delta \mathrm{Np} 63 \alpha$ [68]. However, the molecular mechanism underlying this regulatory pathway remains unknown. As a first step, we propose an investigation of the UBE4B- $\triangle \mathrm{Np} 73$ relationship. Second, the fact that UBE4B has no relation to any of the the $\beta$ isoform of either p63 or $\mathrm{p} 73$ might also explain the specificity of this ligase. In conclusion, the ratio of expression of the p53 family proteins, including those possessing apoptotic 
activity or anti-apoptotic activity, is the key factor in maintaining a stable developmental mechanism for the nervous system. Therefore, regulatory molecules that affect protein expression and activity, such as UBE4B, will be a turning point in the field of neuronal physiology and neurodegenerative disease.

\section{The Role of UBE4B in the Nervous System Is Independent of p53 Family Regulation}

Another characteristic of neurodegenerative diseases is the presence of insoluble aggregates in the neurons due to polyglutamination [71], which is common in Huntington disease, spinobulbar muscular atrophy, dentatorubral-pallidoluysian atrophy, spinocerebellar ataxia, Alzheimer disease, and Parkinson disease $[72,73]$. The intracellular aggregates become conjugated with ubiquitin, altering the conformational structure of target proteins [74]. Because these intracellular aggregates are associated with ubiquitin, all E3/E4 ligases regulating the ubiquitination mechanism become target molecules in this process [74]. However, because these aggregates are detected in neurons [75] and Ube $4 b$ is the only ligase expressed predominantly in the neural tissue of adult mice [24], many scientists have speculated on the role of Ube $4 b$ in this process. These speculations were also supported by other observations, such as the lethality of Ube $4 \mathrm{~b}$ double deletion in mice; Ube $4 \mathrm{~b}^{+/-}$mice also displayed axonal dystrophy in the nucleus gracilis and the degeneration of Purkinje cells in endoplasmic reticulum stress [76]. In parallel, when Ube4b was knocked down, the level of polyubiquitination was remarkedly decreased. Matsumoto et al. were the first to show the role of Ube $4 b$ in polyubiquitinating and degrading ataxin3, whose abnormal expansion of the polyglutamine tract causes spinocerebellar ataxia type 3 [74]. Ube4b showed no difference in the level of ubiquitination in normal or pathological ataxin3, which has an expanded polyglutamine tract; however, this process was shown to be mediated by VCP proteins [74,77]. It was proposed that VCP, ATPase valosin-containing protein [78], mediates the dissociation of Ube $4 \mathrm{~b}$ from ataxin3, inducing its degradation. This dissociation mechanism is blocked for pathological ataxin3, despite polyubiquitination of ataxin3 by Ube4b. Interestingly, VCP, which has previously been shown to exhibit no ligase activity, was proven to be associated with Ube $4 \mathrm{~b}$ and not with any other E3 ligases [74]. Based on that finding, Ube4b is considered to be a rate-limiting factor in mediating the ubiquitination and polygutamine aggregation in neurodegenerative diseases.

Axon degeneration is a consistently common phenotype for many neurodegenerative disorders [79]. Nerve injury, such as lesions, vincristine neuropathy, and myelin-related axonopathies, is always accompanied by direct axon degeneration within two days of the stimulus [80-82]. The Wallerian degeneration process, a non-apoptotic death program, has been shown to chiefly regulate axon degeneration in response to injury [83]. Wallerian degeneration has been proposed to play a prominent causative role in a wide range of human neuropathologies in trauma, spinal cord injury or even at early stages $[84,85]$. Although little is known about Wallerian degeneration and the signals that initiates this pathway, a spontaneous dominant mutation delays Wallerian degeneration ten-fold and is known as slow Wallerian mutation $\left(\mathrm{Wld}^{\mathrm{s}}\right)$ [80,84]. As a result, scientists have concluded that Wallerian degeneration is not a passive process but an active regulated process [86-88]. Furthermore, animal models highly support this hypothesis, and a delay in axonal and even synaptic degeneration was reported in $\mathrm{Wld}^{\mathrm{s}}$ mice $[89,90]$. As in mice, $\mathrm{Wld}^{\mathrm{s}}$ rats display axon survival up to two weeks after transection and remain functional for at least one week [91]. The progression of many diseases, such as axonal injury, Parkinson's disease, and cerebral ischemia, was also altered in $\mathrm{Wld}^{\mathrm{s}}[80,84,92]$. Further 
analysis revealed a significant role of $\mathrm{Wld}^{\mathrm{s}}$, which dominantly delays Wallerian degeneration 10-fold [93], findings have been confirmed in vitro and in vivo [83]. Interestingly, the Wld ${ }^{\mathrm{s}}$ gene encodes chimeric protein composed of 70 amino acids of Ube $4 \mathrm{~b}$ linked to full length nicotinamide mononucleotide adenylyl transferase 1 (Nmnat1) [94]; both moieties have been shown to be essential for the proper function of the $\mathrm{Wld}^{\mathrm{s}}$ protein in delaying degradation $[79,94]$. Importantly, this chimeric protein is missing in wild-type mice [95]. Although the Ube4b region essential to Wld does not contain the $U$ box, it has been demonstrated that Ube4b moiety influences the intracellular distribution of the covalently attached Nmnatl and, consequently, the distribution of nuclear $\mathrm{NAD}^{+}$synthesis machinery [96]. The same portion of Ube $4 b$ has been demonstrated to bind to the VCP protein; 16 of the 70 amino acids form the VCP binding motif. This binding between Ube $4 \mathrm{~b}$ N portion and VCP influences the redistribution of molecules in nuclei in vivo and in vitro when $\mathrm{Wld}^{\mathrm{s}}$ is present [97,98]. Many functions of VCP have been identified, little is known about the role of VCP with regards to the $\mathrm{Wld}^{\mathrm{s}}$ protein and the delay in neural degeneration. However, the role of VCP in Ube $4 b$-ataxin3 dissociation and the binding of $\mathrm{Wld}^{\mathrm{s}}$ proteins through the Ube $4 \mathrm{~b} \mathrm{~N}$ portion focus more attention on the role of VCP in neuronal regulation. This role is exclusively associated with Ube4b because VCP has no association with any other ligases. Further investigation is necessary to elucidate the exact role of VCP. The lack of a chimeric protein raises some possibilities that the Ube $4 b$ portion might be mutated or altered, thus abolishing the formation of the chimeric protein, and further investigations are needed to clarify this as well.

\section{Conclusions}

In conclusion, UBE4B is involved in multiple pathways that are all associated with neuronal survival and degradation. Whether through the p53 family or other processes, UBE4B is definitively implicated in neuronal survival. A model for the role of UBE4B is summarized in the Figure 1. Investigating the exact role of UBE4B and all cofactors associated with its function could contribute to understanding the normal physiology of the nervous system and also be a gateway to many therapeutic and pharmaceutical approaches that aim to treat neurodegenerative diseases by protecting neurons from death as a response to mutation or injury.

Figure 1. Schematic model for UBE4B showing the inhibition $(-)$, stabilization $(\rightarrow)$, or possible relation (?) with p53 family proteins, Wallerian pathway, and polyglutamination in neurodegenerative diseases.

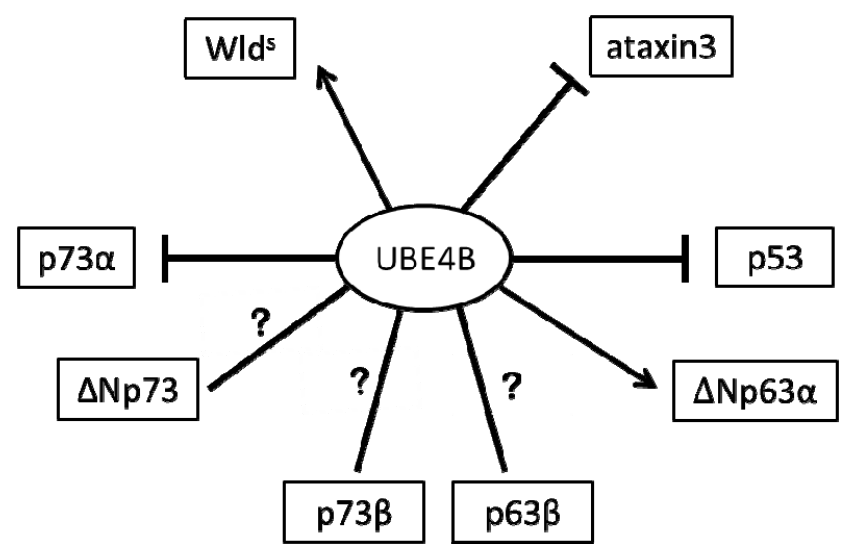




\section{Acknowledgments}

This work is supported by the Canadian Institutes of Health Research and Alberta Innovates Health Solutions (R.L.). R.A.Z. is supported by Alberta Cancer Foundation Graduate Studentship and Women and Children's Health Research Institute Graduate Studentship (WCHRI)/Hair Massacure 2011 Award (University of Alberta).

\section{References}

1. Yuan, J.; Yankner, B.A. Apoptosis in the nervous system. Nature 2000, 407, 802-809.

2. Jacobs, W.B.; Kaplan, D.R.; Miller, F.D. The p53 family in nervous system development and disease. J. Neurochem. 2006, 97, 1571-1584.

3. Blaschke, A.J.; Staley, K.; Chun, J. Widespread programmed cell death in proliferative and postmitotic regions of the fetal cerebral cortex. Development 1996, 122, 1165-1174.

4. Gilmore, E.C.; Nowakowski, R.S.; Caviness, V.S., Jr.; Herrup, K. Cell birth, cell death, cell diversity and DNA breaks: How do they all fit together? Trends Neurosci. 2000, 23, 100-105.

5. Jacobs, W.B.; Walsh, G.S.; Miller, F.D. Neuronal survival and p73/p63/p53: A family affair. Neuroscientist 2004, 10, 443-455.

6. Wood, K.A.; Youle, R.J. The role of free radicals and p53 in neuron apoptosis in vivo. J. Neurosci. 1995, 15, 5851-5857.

7. Graham, S.H.; Chen, J. Programmed cell death in cerebral ischemia. J. Cereb. Blood Flow Metab. 2001, 21, 99-109.

8. Green, D.R. Apoptotic pathways: The roads to ruin. Cell 1998, 94, 695-698.

9. Johnstone, R.W.; Ruefli, A.A.; Lowe, S.W. Apoptosis: A link between cancer genetics and chemotherapy. Cell 2002, 108, 153-164.

10. Soussi, T. The p53 pathway and human cancer. Br. J. Surg. 2005, 92, 1331-1332.

11. Vogelstein, B.; Lane, D.; Levine, A.J. Surfing the p53 network. Nature 2000, 408, 307-310.

12. Carter, S.; Vousden, K.H. p53-Ubl fusions as models of ubiquitination, sumoylation and neddylation of p53. Cell Cycle 2008, 7, 2519-2528.

13. Wu, H.; Pomeroy, S.L.; Ferreira, M.; Teider, N.; Mariani, J.; Nakayama, K.I.; Hatakeyama, S.; Tron, V.A.; Saltibus, L.F.; Spyracopoulos, L.; et al. UBE4B promotes Hdm2-mediated degradation of the tumor suppressor p53. Nat. Med. 2011, 17, 347-355.

14. Gostissa, M.; Hengstermann, A.; Fogal, V.; Sandy, P.; Schwarz, S.E.; Scheffner, M.; del Sal, G. Activation of $\mathrm{p} 53$ by conjugation to the ubiquitin-like protein SUMO-1. EMBO J. 1999, 18, 6462-6471.

15. Rodriguez, M.S.; Desterro, J.M.; Lain, S.; Midgley, C.A.; Lane, D.P.; Hay, R.T. SUMO-1 modification activates the transcriptional response of p53. EMBO J. 1999, 18, 6455-6461.

16. Shen, L.N.; Liu, H.; Dong, C.; Xirodimas, D.; Naismith, J.H.; Hay, R.T. Structural basis of NEDD8 ubiquitin discrimination by the deNEDDylating enzyme NEDP1. EMBO J. 2005, 24, 1341-1351.

17. Whitby, F.G.; Xia, G.; Pickart, C.M.; Hill, C.P. Crystal structure of the human ubiquitin-like protein NEDD8 and interactions with ubiquitin pathway enzymes. J. Biol. Chem. 1998, 273, 34983-34991. 
18. Feng, L.; Lin, T.; Uranishi, H.; Gu, W.; Xu, Y. Functional analysis of the roles of posttranslational modifications at the p53 C terminus in regulating p53 stability and activity. Mol. Cell. Biol. 2005, 25, 5389-5395.

19. Ozeki, C.; Sawai, Y.; Shibata, T.; Kohno, T.; Okamoto, K.; Yokota, J.; Tashiro, F.; Tanuma, S.; Sakai, R.; Kawase, T.; et al. Cancer susceptibility polymorphism of p53 at codon 72 affects phosphorylation and degradation of p53 protein. J. Biol. Chem. 2011, 286, 18251-18260.

20. Yang, Y.; Li, C.C.; Weissman, A.M. Regulating the p53 system through ubiquitination. Oncogene 2004, 23, 2096-2106.

21. Watson, I.R.; Irwin, M.S. Ubiquitin and ubiquitin-like modifications of the p53 family. Neoplasia 2006, 8, 655-666.

22. Tan, J.M.; Wong, E.S.; Kirkpatrick, D.S.; Pletnikova, O.; Ko, H.S.; Tay, S.P.; Ho, M.W.; Troncoso, J.; Gygi, S.P.; Lee, M.K.; et al. Lysine 63-linked ubiquitination promotes the formation and autophagic clearance of protein inclusions associated with neurodegenerative diseases. Hum. Mol. Genet. 2008, 17, 431-439.

23. Zeng, X.; Chen, L.; Jost, C.A.; Maya, R.; Keller, D.; Wang, X.; Kaelin, W.G., Jr.; Oren, M.; Chen, J.; Lu, H. MDM2 suppresses p73 function without promoting p73 degradation. Mol. Cell. Biol. 1999, 19, 3257-3266.

24. Kaneko, C.; Hatakeyama, S.; Matsumoto, M.; Yada, M.; Nakayama, K.; Nakayama, K.I. Characterization of the mouse gene for the U-box-type ubiquitin ligase UFD2a. Biochem. Biophys. Res. Commun. 2003, 300, 297-304.

25. Donehower, L.A.; Harvey, M.; Slagle, B.L.; McArthur, M.J.; Montgomery, C.A., Jr.; Butel, J.S.; Bradley, A. Mice deficient for p53 are developmentally normal but susceptible to spontaneous tumours. Nature 1992, 356, 215-221.

26. Armstrong, J.F.; Kaufman, M.H.; Harrison, D.J.; Clarke, A.R. High-frequency developmental abnormalities in p53-deficient mice. Curr. Biol. 1995, 5, 931-936.

27. Sah, V.P.; Attardi, L.D.; Mulligan, G.J.; Williams, B.O.; Bronson, R.T.; Jacks, T. A subset of p53-deficient embryos exhibit exencephaly. Nat. Genet. 1995, 10, 175-180.

28. Mihara, M.; Erster, S.; Zaika, A.; Petrenko, O.; Chittenden, T.; Pancoska, P.; Moll, U.M. p53 has a direct apoptogenic role at the mitochondria. Mol. Cell 2003, 11, 577-590.

29. Cecconi, F.; Alvarez-Bolado, G.; Meyer, B.I.; Roth, K.A.; Gruss, P. Apaf1 (CED-4 homolog) regulates programmed cell death in mammalian development. Cell 1998, 94, 727-737.

30. Kuida, K.; Haydar, T.F.; Kuan, C.Y.; Gu, Y.; Taya, C.; Karasuyama, H.; Su, M.S.; Rakic, P.; Flavell, R.A. Reduced apoptosis and cytochrome c-mediated caspase activation in mice lacking caspase 9. Cell 1998, 94, 325-337.

31. Yoshida, H.; Kong, Y.Y.; Yoshida, R.; Elia, A.J.; Hakem, A.; Hakem, R.; Penninger, J.M.; Mak, T.W. Apaf1 is required for mitochondrial pathways of apoptosis and brain development. Cell 1998, 94, 739-750.

32. Kuida, K.; Zheng, T.S.; Na, S.; Kuan, C.; Yang, D.; Karasuyama, H.; Rakic, P.; Flavell, R.A. Decreased apoptosis in the brain and premature lethality in CPP32-deficient mice. Nature 1996, $384,368-372$. 
33. Slack, R.S.; Belliveau, D.J.; Rosenberg, M.; Atwal, J.; Lochmuller, H.; Aloyz, R.; Haghighi, A.; Lach, B.; Seth, P.; Cooper, E.; et al. Adenovirus-mediated gene transfer of the tumor suppressor, p53, induces apoptosis in postmitotic neurons. J. Cell Biol. 1996, 135, 1085-1096.

34. Miller, F.D.; Kaplan, D.R. On Trk for retrograde signaling. Neuron 2001, 32, 767-770.

35. Aloyz, R.S.; Bamji, S.X.; Pozniak, C.D.; Toma, J.G.; Atwal, J.; Kaplan, D.R.; Miller, F.D. p53 is essential for developmental neuron death as regulated by the TrkA and p75 neurotrophin receptors. J. Cell Biol. 1998, 143, 1691-1703.

36. Lee, Y.; McKinnon, P.J. Detection of apoptosis in the central nervous system. Methods Mol. Biol. 2009, 559, 273-282.

37. Chopp, M.; Li, Y.; Zhang, Z.G.; Freytag, S.O. p53 expression in brain after middle cerebral artery occlusion in the rat. Biochem. Biophys. Res. Commun. 1992, 182, 1201-1207.

38. Watanabe, H.; Ohta, S.; Kumon, Y.; Sakaki, S.; Sakanaka, M. Increase in p53 protein expression following cortical infarction in the spontaneously hypertensive rat. Brain Res. 1999, 837, 38-45.

39. Martin, L.J. p53 is abnormally elevated and active in the CNS of patients with amyotrophic lateral sclerosis. Neurobiol. Dis. 2000, 7, 613-622.

40. Levrero, M.; de Laurenzi, V.; Costanzo, A.; Gong, J.; Wang, J.Y.; Melino, G. The p53/p63/p73 family of transcription factors: Overlapping and distinct functions. J. Cell Sci. 2000, 113, 1661-1670.

41. Wu, H.; Leng, R.P. UBE4B, a ubiquitin chain assembly factor, is required for MDM2-mediated p53 polyubiquitination and degradation. Cell Cycle 2011, 10, 1912-1915.

42. Saeki, Y.; Kudo, T.; Sone, T.; Kikuchi, Y.; Yokosawa, H.; Toh-e, A.; Tanaka, K. Lysine 63-linked polyubiquitin chain may serve as a targeting signal for the $26 \mathrm{~S}$ proteasome. EMBO J. 2009, 28, 359-371.

43. Wu, H.; Zeinab, R.A.; Flores, E.R.; Leng, R.P. Pirh2, a ubiquitin E3 ligase, inhibits p73 transcriptional activity by promoting its ubiquitination. Mol. Cancer Res. 2011, 9, 1780-1790.

44. Melino, G.; de Laurenzi, V.; Vousden, K.H. p73: Friend or foe in tumorigenesis. Nat. Rev. Cancer 2002, 2, 605-615.

45. Yang, A.; Walker, N.; Bronson, R.; Kaghad, M.; Oosterwegel, M.; Bonnin, J.; Vagner, C.; Bonnet, H.; Dikkes, P.; Sharpe, A.; McKeon, F.; Caput, D. p73-deficient mice have neurological, pheromonal and inflammatory defects but lack spontaneous tumours. Nature 2000, 404, 99-103.

46. Flores, E.R.; Tsai, K.Y.; Crowley, D.; Sengupta, S.; Yang, A.; McKeon, F.; Jacks, T. p63 and p73 are required for p53-dependent apoptosis in response to DNA damage. Nature 2002, 416, 560-564.

47. Jost, C.A.; Marin, M.C.; Kaelin, W.G., Jr. p73 is a simian (correction of human) p53-related protein that can induce apoptosis. Nature 1997, 389, 191-194.

48. Pozniak, C.D.; Radinovic, S.; Yang, A.; McKeon, F.; Kaplan, D.R.; Miller, F.D. An anti-apoptotic role for the p53 family member, p73, during developmental neuron death. Science 2000, 289, 304-306.

49. Walsh, G.S.; Orike, N.; Kaplan, D.R.; Miller, F.D. The invulnerability of adult neurons: A critical role for p73. J. Neurosci. 2004, 24, 9638-9647.

50. Irwin, M.S.; Miller, F.D. p73: Regulator in cancer and neural development. Cell Death Differ. 2004, 11, S17-S22. 
51. Wilson, C.; Henry, S.; Smith, M.A.; Bowser, R. The p53 homologue p73 accumulates in the nucleus and localizes to neurites and neurofibrillary tangles in Alzheimer disease brain. Neuropathol. Appl. Neurobiol. 2004, 30, 19-29.

52. Zaika, A.I.; Slade, N.; Erster, S.H.; Sansome, C.; Joseph, T.W.; Pearl, M.; Chalas, E.; Moll, U.M. DeltaNp73, a dominant-negative inhibitor of wild-type p53 and TAp73, is up-regulated in human tumors. J. Exp. Med. 2002, 196, 765-780.

53. Nakagawa, T.; Takahashi, M.; Ozaki, T.; Watanabe K.-i.; Todo, S.; Mizuguchi, H.; Hayakawa, T.; Nakagawara, A. Autoinhibitory regulation of p73 by $\Delta \mathrm{Np} 73$ to modulate cell survival and death through a p73-specific target element within the Delta Np73 promoter. Mol. Cell. Biol. 2002, 22, 2575-2585.

54. Grob, T.J.; Novak, U.; Maisse, C.; Barcaroli, D.; Luthi, A.U.; Pirnia, F.; Hugli, B.; Graber, H.U.; de Laurenzi, V.; Fey, M.F.; et al. Human delta Np73 regulates a dominant negative feedback loop for TAp73 and p53. Cell Death Differ. 2001, 8, 1213-1223.

55. Fillippovich, I.; Sorokina, N.; Gatei, M.; Haupt, Y.; Hobson, K.; Moallem, E.; Spring, K.; Mould, M.;

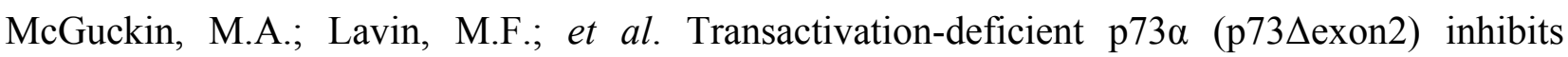
apoptosis and competes with p53. Oncogene 2001, 20, 514-522.

56. Irwin, M.S.; Kaelin, W.G. p53 family update: p73 and p63 develop their own identities. Cell Growth Differ. 2001, 12, 337-349.

57. Hosoda, M.; Ozaki, T.; Miyazaki, K.; Hayashi, S.; Furuya, K.; Watanabe, K.; Nakagawa, T.; Hanamoto, T.; Todo, S.; Nakagawara, A. UFD2a mediates the proteasomal turnover of p73 without promoting p73 ubiquitination. Oncogene 2005, 24, 7156-7169.

58. Ozaki, T.; Hosoda, M.; Miyazaki, K.; Hayashi, S.; Watanabe, K.; Nakagawa, T.; Nakagawara, A. Functional implication of p73 protein stability in neuronal cell survival and death. Cancer Lett. 2005, 228, 29-35.

59. Lee, A.F.; Ho, D.K.; Zanassi, P.; Walsh, G.S.; Kaplan, D.R.; Miller, F.D. Evidence that $\Delta \mathrm{Np} 73$ promotes neuronal survival by p53-dependent and p53-independent mechanisms. J. Neurosci. 2004, 24, 9174-9184.

60. Kaplan, D.R.; Miller, F.D. Neurotrophin signal transduction in the nervous system. Curr. Opin. Neurobiol. 2000, 10, 381-391.

61. Jacobs, W.B.; Govoni, G.; Ho, D.; Atwal, J.K.; Barnabe-Heider, F.; Keyes, W.M.; Mills, A.A.; Miller, F.D.; Kaplan, D.R. p63 is an essential proapoptotic protein during neural development. Neuron 2005, 48, 743-756.

62. Nicotera, P.; Melino, G. Neurodevelopment on route p63. Neuron 2005, 48, 707-709.

63. Gressner, O.; Schilling, T.; Lorenz, K.; Schleithoff, E.S.; Koch, A.; Schulze-Bergkamen, H.; Lena, A.M.; Candi, E.; Terrinoni, A.; Catani, M.V.; et al. TAp63 $\alpha$ induces apoptosis by activating signaling via death receptors and mitochondria. EMBO J. 2005, 24, 2458-2471.

64. King, K.E.; Ponnamperuma, R.M.; Yamashita, T.; Tokino, T.; Lee, L.A.; Young, M.F.; Weinberg, W.C. $\Delta \mathrm{Np} 63 \alpha$ functions as both a positive and a negative transcriptional regulator and blocks in vitro differentiation of murine keratinocytes. Oncogene 2003, 22, 3635-3644.

65. Yamaguchi, K.; Wu, L.; Caballero, O.L.; Hibi, K.; Trink, B.; Resto, V.; Cairns, P.; Okami, K.; Koch, W.M.; Sidransky, D.; et al. Frequent gain of the p40/p51/p63 gene locus in primary head and neck squamous cell carcinoma. Int. J. Cancer 2000, 86, 684-689. 
66. Pelosi, G.; Pasini, F.; Stenholm, C.S.; Pastorino, U.; Maisonneuve, P.; Sonzogni, A.; Maffini, F.; Pruneri, G.; Fraggetta, F.; Cavallon, A.; et al. p63 immunoreactivity in lung cancer: Yet another player in the development of squamous cell carcinomas? J. Pathol. 2002, 198, 100-109.

67. Crook, T.; Nicholls, J.M.; Brooks, L.; O’Nions, J.; Allday, M.J. High level expression of $\delta \mathrm{N}-\mathrm{p} 63$ : A mechanism for the inactivation of p53 in undifferentiated nasopharyngeal carcinoma (NPC)? Oncogene 2000, 19, 3439-3444.

68. Chatterjee, A.; Upadhyay, S.; Chang, X.; Nagpal, J.K.; Trink, B.; Sidransky, D. U-box-type ubiquitin E4 ligase, UFD2a attenuates cisplatin mediated degradation of $\Delta \mathrm{Np} 63 \alpha$. Cell Cycle 2008, 7, 1231-1237.

69. Westfall, M.D.; Joyner, A.S.; Barbieri, C.E.; Livingstone, M.; Pietenpol, J.A. Ultraviolet radiation induces phosphorylation and ubiquitin-mediated degradation of $\delta \mathrm{Np} 63 \alpha$. Cell Cycle 2005, 4, 710-716.

70. Osada, M.; Inaba, R.; Shinohara, H.; Hagiwara, M.; Nakamura, M.; Ikawa, Y. Regulatory domain of protein stability of human P51/TAP63, a P53 homologue. Biochem. Biophys Res. Commun. 2001, 283, 1135-1141.

71. Koshy, B.T.; Zoghbi, H.Y. The CAG/polyglutamine tract diseases: Gene products and molecular pathogenesis. Brain Pathol. 1997, 7, 927-942.

72. Alves-Rodrigues, A.; Gregori, L.; Figueiredo-Pereira, M.E. Ubiquitin, cellular inclusions and their role in neurodegeneration. Trends Neurosci. 1998, 21, 516-520.

73. Hayashi, Y.; Kakita, A.; Yamada, M.; Koide, R.; Igarashi, S.; Takano, H.; Ikeuchi, T.; Wakabayashi, K.; Egawa, S.; Tsuji, S.; et al. Hereditary dentatorubral-pallidoluysian atrophy: Detection of widespread ubiquitinated neuronal and glial intranuclear inclusions in the brain. Acta Neuropathol. 1998, 96, 547-552.

74. Matsumoto, M.; Yada, M.; Hatakeyama, S.; Ishimoto, H.; Tanimura, T.; Tsuji, S.; Kakizuka, A.; Kitagawa, M.; Nakayama, K.I. Molecular clearance of ataxin-3 is regulated by a mammalian E4. EMBO J. 2004, 23, 659-669.

75. Lunkes, A.; Mandel, J.L. Polyglutamines, nuclear inclusions and neurodegeneration. Nat. Med. 1997, 3, 1201-1202.

76. Kaneko-Oshikawa, C.; Nakagawa, T.; Yamada, M.; Yoshikawa, H.; Matsumoto, M.; Yada, M.; Hatakeyama, S.; Nakayama, K.; Nakayama, K.I. Mammalian E4 is required for cardiac development and maintenance of the nervous system. Mol. Cell. Biol. 2005, 25, 10953-10964.

77. Morreale, G.; Conforti, L.; Coadwell, J.; Wilbrey, A.L.; Coleman, M.P. Evolutionary divergence of valosin-containing protein/cell division cycle protein 48 binding interactions among endoplasmic reticulum-associated degradation proteins. FEBS J. 2009, 276, 1208-1220.

78. Dai, R.M.; Li, C.C. Valosin-containing protein is a multi-ubiquitin chain-targeting factor required in ubiquitin-proteasome degradation. Nat. Cell Biol. 2001, 3, 740-744.

79. Conforti, L.; Wilbrey, A.; Morreale, G.; Janeckova, L.; Beirowski, B.; Adalbert, R.; Mazzola, F.; di Stefano, M.; Hartley, R.; Babetto, E.; et al. Wld S protein requires Nmnat activity and a short $\mathrm{N}$-terminal sequence to protect axons in mice. J. Cell Biol. 2009, 184, 491-500.

80. Ferri, A.; Sanes, J.R.; Coleman, M.P.; Cunningham, J.M.; Kato, A.C. Inhibiting axon degeneration and synapse loss attenuates apoptosis and disease progression in a mouse model of motoneuron disease. Curr. Biol. 2003, 13, 669-673. 
81. Samsam, M.; Mi, W.; Wessig, C.; Zielasek, J.; Toyka, K.V.; Coleman, M.P.; Martini, R. The Wlds mutation delays robust loss of motor and sensory axons in a genetic model for myelin-related axonopathy. J. Neurosci. 2003, 23, 2833-2839.

82. Wang, M.; Wu, Y.; Culver, D.G.; Glass, J.D. The gene for slow Wallerian degeneration (Wld(s)) is also protective against vincristine neuropathy. Neurobiol. Dis. 2001, 8, 155-161.

83. Coleman, M. Axon degeneration mechanisms: Commonality amid diversity. Nat. Rev. Neurosci. 2005, 6, 889-898.

84. Mack, T.G.; Reiner, M.; Beirowski, B.; Mi, W.; Emanuelli, M.; Wagner, D.; Thomson, D.; Gillingwater, T.; Court, F.; Conforti, L.; et al. Wallerian degeneration of injured axons and synapses is delayed by a Ube4b/Nmnat chimeric gene. Nat. Neurosci. 2001, 4, 1199-1206.

85. Zhang, Z.; Fujiki, M.; Guth, L.; Steward, O. Genetic influences on cellular reactions to spinal cord injury: A wound-healing response present in normal mice is impaired in mice carrying a mutation (WldS) that causes delayed Wallerian degeneration. J. Comp. Neurol. 1996, 371, 485-495.

86. Glass, J.D.; Brushart, T.M.; George, E.B.; Griffin, J.W. Prolonged survival of transected nerve fibres in C57BL/Ola mice is an intrinsic characteristic of the axon. J. Neurocytol. 1993, 22, 311-321.

87. Buckmaster, E.A.; Perry, V.H.; Brown, M.C. The rate of Wallerian degeneration in cultured neurons from wild type and C57BL/WldS mice depends on time in culture and may be extended in the presence of elevated $\mathrm{K}^{+}$levels. Eur. J. Neurosci. 1995, 7, 1596-1602.

88. Perry, V.H.; Brown, M.C.; Lunn, E.R.; Tree, P.; Gordon, S. Evidence that very slow wallerian degeneration in $\mathrm{C} 57 \mathrm{BL} / \mathrm{Ola}$ mice is an intrinsic property of the peripheral nerve. Eur. J. Neurosci. 1990, 2, 802-808.

89. Gillingwater, T.H.; Ribchester, R.R. Compartmental neurodegeneration and synaptic plasticity in the Wld(s) mutant mouse. J. Physiol. 2001, 534, 627-639.

90. Gillingwater, T.H.; Thomson, D.; Mack, T.G.; Soffin, E.M.; Mattison, R.J.; Coleman, M.P.; Ribchester, R.R. Age-dependent synapse withdrawal at axotomised neuromuscular junctions in Wld(s) mutant and Ube4b/Nmnat transgenic mice. J. Physiol. 2002, 543, 739-755.

91. Adalbert, R.; Gillingwater, T.H.; Haley, J.E.; Bridge, K.; Beirowski, B.; Berek, L.; Wagner, D.; Grumme, D.; Thomson, D.; Celik, A.; et al. A rat model of slow Wallerian degeneration (WldS) with improved preservation of neuromuscular synapses. Eur. J. Neurosci. 2005, 21, 271-277.

92. Deckwerth, T.L.; Johnson, E.M., Jr. Neurites can remain viable after destruction of the neuronal soma by programmed cell death (apoptosis). Dev. Biol. 1994, 165, 63-72.

93. Lunn, E.R.; Perry, V.H.; Brown, M.C.; Rosen, H.; Gordon, S. Absence of Wallerian Degeneration does not Hinder Regeneration in Peripheral Nerve. Eur. J. Neurosci. 1989, 1, 27-33.

94. Conforti, L.; Fang, G.; Beirowski, B.; Wang, M.S.; Sorci, L.; Asress, S.; Adalbert, R.; Silva, A.; Bridge, K.; Huang, X.P.; et al. $\mathrm{NAD}(+)$ and axon degeneration revisited: Nmnat1 cannot substitute for Wld(S) to delay Wallerian degeneration. Cell Death Differ. 2007, 14, 116-127.

95. Emanuelli, M.; Carnevali, F.; Saccucci, F.; Pierella, F.; Amici, A.; Raffaelli, N.; Magni, G. Molecular cloning, chromosomal localization, tissue mRNA levels, bacterial expression, and enzymatic properties of human NMN adenylyltransferase. J. Biol. Chem. 2001, 276, 406-412. 
96. Sasaki, Y.; Vohra, B.P.; Lund, F.E.; Milbrandt, J. Nicotinamide mononucleotide adenylyl transferase-mediated axonal protection requires enzymatic activity but not increased levels of neuronal nicotinamide adenine dinucleotide. J. Neurosci. 2009, 29, 5525-5535.

97. Laser, H.; Conforti, L.; Morreale, G.; Mack, T.G.; Heyer, M.; Haley, J.E.; Wishart, T.M.; Beirowski, B.; Walker, S.A.; Haase, G.; et al. The slow Wallerian degeneration protein, WldS, binds directly to VCP/p97 and partially redistributes it within the nucleus. Mol. Biol. Cell 2006, 17, 1075-1084.

98. Wilbrey, A.L.; Haley, J.E.; Wishart, T.M.; Conforti, L.; Morreale, G.; Beirowski, B.; Babetto, E.; Adalbert, R.; Gillingwater, T.H.; Smith, T.; et al. VCP binding influences intracellular distribution of the slow Wallerian degeneration protein, Wld(S). Mol. Cell. Neurosci. 2008, 38, $325-340$.

(C) 2012 by the authors; licensee MDPI, Basel, Switzerland. This article is an open access article distributed under the terms and conditions of the Creative Commons Attribution license (http://creativecommons.org/licenses/by/3.0/). 